Check for updates

Cite this: Chem. Sci., 2019, 10, 4923

๑ All publication charges for this article have been paid for by the Royal Society of Chemistry

Received 14th November 2018 Accepted 31st March 2019

DOI: $10.1039 / \mathrm{c} 8 \mathrm{sc} 05088 \mathrm{k}$

rsc.li/chemical-science

\title{
Functionality in metal-organic framework minerals: proton conductivity, stability and potential for polymorphism $\dagger$
}

\author{
Igor Huskić, (iD a Novendra Novendra, ${ }^{b}$ Dae-Woon Lim, (D) ${ }^{c}$ Filip Topić, (D) ${ }^{a}$ \\ Hatem M. Titi, (D) a Igor V. Pekov, ${ }^{d}$ Sergey V. Krivovichev, ${ }^{\text {e }}$ Alexandra Navrotsky, (D) *b \\ Hiroshi Kitagawa (iD) ${ }^{* c}$ and Tomislav Friščić (DD *a
}

\begin{abstract}
Rare metal-organic framework (MOF) minerals stepanovite and zhemchuzhnikovite can exhibit properties comparable to known oxalate MOF proton conductors, including high proton conductivity over a range of relative humidities at $25^{\circ} \mathrm{C}$, and retention of the framework structure upon thermal dehydration. They also have high thermodynamic stability, with a pronounced stabilizing effect of substituting aluminium for iron, illustrating a simple design to access stable, highly proton-conductive MOFs without using complex organic ligands.
\end{abstract}

\section{Introduction}

Whereas most minerals are inorganic solids, ${ }^{1}$ recent work highlighted complex organic or metal-organic structures of minerals found in unusual or extreme environments. ${ }^{2}$ Examples include mellitic acid on Mars, ${ }^{3}$ hydrocarbon cocrystals as prospective minerals on Titan, ${ }^{\mathbf{4}}$ metal oxalate coordination polymers (humboldtine, lindbergite), ${ }^{5}$ or geoporphyrins (abelsonite). ${ }^{6}$ The search to discover and understand the properties of such non-conventional minerals has been galvanized by the Carbon Mineral Challenge project, ${ }^{7}$ exploring the role of carbon in mineral and biological evolution on Earth and other planets. ${ }^{8}$ A recent addition to this set of unusual natural structures are metal-organic frameworks (MOFs) in the form of rare minerals zhemchuzhnikovite $(\mathbf{Z H}$, $\left.\left[\mathrm{Mg}\left(\mathrm{H}_{2} \mathrm{O}\right)_{6}\right]\left[\mathrm{NaFe}_{x} \mathrm{Al}_{1-x}\left(\mathrm{C}_{2} \mathrm{O}_{4}\right)_{3}\right] \cdot 3 \mathrm{H}_{2} \mathrm{O}, x \sim 0.6\right)$ and stepanovite (ST, $\left.\left[\mathrm{Mg}\left(\mathrm{H}_{2} \mathrm{O}\right)_{6}\right]\left[\mathrm{NaFe}\left(\mathrm{C}_{2} \mathrm{O}_{4}\right)_{3}\right] \cdot 3 \mathrm{H}_{2} \mathrm{O}\right)$, discovered in the Lower Lena region of Siberia., ${ }^{9,10}$ Single crystal X-ray diffraction analysis of natural samples reveals that the minerals are based on open two-dimensional (2-D) honeycomb (3,6)-topology

\footnotetext{
${ }^{a}$ Department of Chemistry, McGill University, Montreal, Canada. E-mail: tomislav. friscic@mcgill.ca

${ }^{b}$ Peter A. Rock Thermochemistry Laboratory and NEAT ORU, University of California Davis, Davis, CA, USA. E-mail: anavrotsky@ucdavis.edu

'Division of Chemistry, Graduate School of Science, Kyoto University, KitashirakawaOiwakecho, Sakyo-ku, Kyoto, 606-8502 Japan.E-mail:kitagawa@kuchem.kyoto-u.ac. jp

${ }^{d}$ Kola Science Centre, Russian Academy of Sciences, Apatity and Department of Crystallography, Saint Petersburg State University, Saint Petersburg, Russia

${ }^{e}$ Faculty of Geology, Lomonosov Moscow State University, Moscow, Russia

$\dagger$ Electronic supplementary information (ESI) available. CCDC 1868681-1868685. For ESI and crystallographic data in CIF or other electronic format see DOI: $10.1039 / \mathrm{c} 8 \mathrm{sc} 05088 \mathrm{k}$
}

(hcb-topology) anionic nets composed of oxalate linkers and a combination of $\mathrm{Na}^{+}$with either only $\mathrm{Fe}^{3+}$ (in ST) or a mixture of $\mathrm{Al}^{3+}$ and $\mathrm{Fe}^{3+}$ nodes (in $\mathbf{Z H}$ ) (Fig. 1a). ${ }^{11}$ The sheets are separated by layers of ordered guest water molecules, and charge-balanced by $\mathrm{Mg}\left(\mathrm{H}_{2} \mathrm{O}\right)_{6}{ }^{2+}$ ions located in cavities of each hcb-sheet. These structures are hybrid organic-inorganic materials analogous to oxalate MOFs investigated for optical, magnetic and particularly proton-conductive properties. ${ }^{12,13}$ The structural similarity raises the exciting possibility that $\mathbf{Z H}$ and $\mathbf{S T}$ minerals should exhibit functional properties expected for related MOFs, notably proton conductivity and stability upon heating or guest removal. ${ }^{\mathbf{1 1 , 1 4}}$

However, scarcity of the minerals has prevented the measurement of their properties. Moreover, while it was reported that $\mathbf{Z H}$ and ST undergo reversible loss of guest water molecules, ${ }^{\mathbf{1 1}}$ there has been no evidence that such dehydration proceeds with retention of the hcb-networks, which would be expected in a functional MOF material. ${ }^{14}$

We now show that $\mathbf{Z H}$ and $\mathbf{S T}$ can indeed exhibit functional behavior on par with known oxalate MOF proton conductors. Specifically, synthetic mineral analogues exhibit high proton conductivities at room temperature, undergo thermal removal of included water guests without changes to the underlying hcbnetworks and, by using solution calorimetry, we demonstrate they are also of high thermodynamic stability.

\section{Experimental}

All reagents were available commercially and were used without additional purification. Oxalic acid, $\mathrm{NaOH}, \mathrm{NaHCO}_{3}, \mathrm{MgO}$, $\mathrm{MgCl}_{2} \cdot 6 \mathrm{H}_{2} \mathrm{O}$ and $\mathrm{FeCl}_{3} \cdot 6 \mathrm{H}_{2} \mathrm{O}$ were obtained from Sigma Aldrich. 

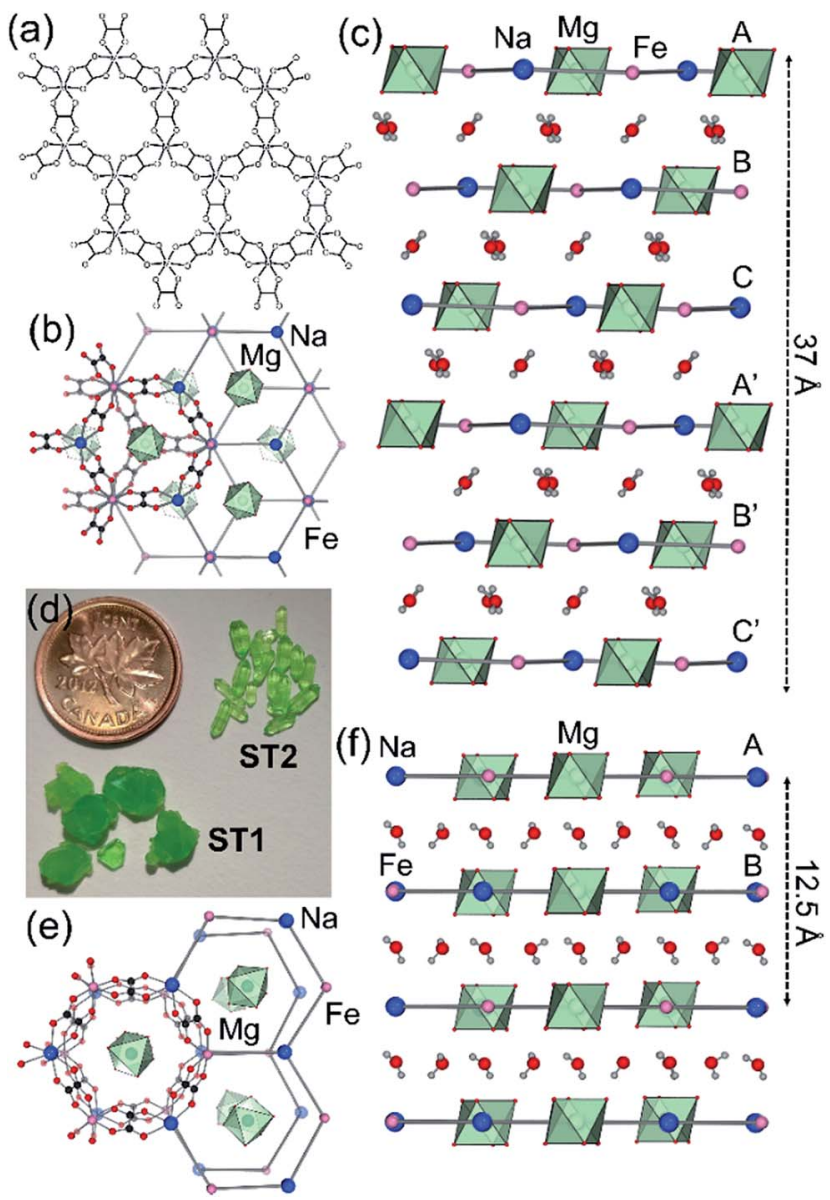

Fig. 1 (a) Scheme of hcb-layers in stepanovite and zhemchuzhnikovite; (b) hcb-layers in synthetic stepanovite (ST1) viewed along and (c) perpendicular to the crystallographic $c$-axis, showing $A B C A^{\prime} B^{\prime} C^{\prime}$ stacking. (d) Samples of ST1 and ST2 shown next to a Canada penny coin ( 1.9 cm diameter) for size comparison; (e) hcb-layers in ST2 viewed parallel to the $c$-axis, showing channel formation and (f) perpendicular to the $c$-axis, showing $A B$ stacking. Green octahedra represent coordination environments of $\mathrm{Mg}\left(\mathrm{H}_{2} \mathrm{O}\right)_{6}{ }^{2+}$ ions.

\section{Synthesis of ST1 and ST2}

Synthesis of ST1 and ST2 was performed by dissolving $\mathrm{FeO}(\mathrm{OH})$ (first obtained by mixing of aqueous solutions of $\mathrm{FeCl}_{3} \cdot 6 \mathrm{H}_{2} \mathrm{O}$ and $\mathrm{NaHCO}_{3}$, followed by filtration) in an aqueous solution of oxalic acid. After addition of $\mathrm{NaOH}$ and $\mathrm{MgCl}_{2} \cdot 6 \mathrm{H}_{2} \mathrm{O}$, the solution was filtered and placed in a refrigerator at $4{ }^{\circ} \mathrm{C}$ for crystallization and slow evaporation. The resulting ST1 and ST2 crystals were separated by hand, based on crystal morphology. Slow evaporation led to mixtures containing ST1 as the major product, while faster evaporation, e.g. in a rotary evaporator, gave ST2 as the major product.

\section{Synthesis of ZH}

Synthesis of $\mathbf{Z H}$ was performed in two steps. In the first step, $\mathrm{NaMgAl}\left(\mathrm{C}_{2} \mathrm{O}_{4}\right)_{3} \cdot 9 \mathrm{H}_{2} \mathrm{O}$ was obtained by dissolving aluminum metal in an aqueous solution of oxalic acid with sonication, followed by addition of $\mathrm{NaOH}, \mathrm{MgCl}_{2} \cdot 6 \mathrm{H}_{2} \mathrm{O}$ and filtration.
Evaporation of the liquid led to crystallization of $\mathrm{NaMgAl}\left(\mathrm{C}_{2}\right.$ $\left.\mathrm{O}_{4}\right)_{3} \cdot 9 \mathrm{H}_{2} \mathrm{O}$, isolated by filtration. In the second step, equivalent amounts of $\mathrm{NaMgAl}\left(\mathrm{C}_{2} \mathrm{O}_{4}\right)_{3} \cdot 9 \mathrm{H}_{2} \mathrm{O}$ and $\mathrm{NaMgFe}\left(\mathrm{C}_{2} \mathrm{O}_{4}\right)_{3} \cdot 9 \mathrm{H}_{2} \mathrm{O}$ (synthesized as described for ST1 and ST2 above) were dissolved in a small amount of water. After several days at $4{ }^{\circ} \mathrm{C}$, yellowgreen needles of $\mathbf{Z H}$ were isolated. Bulk $\mathbf{Z H}$ sample was obtained by milling equimolar amounts of $\mathrm{NaMgAl}\left(\mathrm{C}_{2} \mathrm{O}_{4}\right)_{3} \cdot 9 \mathrm{H}_{2} \mathrm{O}$ and $\mathrm{NaMgFe}\left(\mathrm{C}_{2} \mathrm{O}_{4}\right)_{3} \cdot 9 \mathrm{H}_{2} \mathrm{O}$ with $40 \mu \mathrm{L} \mathrm{H}_{2} \mathrm{O}$ for $30 \mathrm{~min}$ in $10 \mathrm{~mL}$ Teflon ${ }^{\circledR}$ jars with one zirconia ball $(10 \mathrm{~mm}$ diameter $)$ at $25 \mathrm{~Hz}$.

\section{Dehydration of ST1 and ST2 single crystals}

Dehydration of ST1 and ST2 single crystals was performed with gentle heating at $50{ }^{\circ} \mathrm{C}$ under vacuum over a period of 12 hours. The compounds are further denoted as ST1d and ST2d denoting dehydrated $\mathbf{S T 1}$ and $\mathbf{S T 2}$ respectively.

\section{Powder X-ray diffraction (PXRD)}

Powder X-ray diffraction (PXRD) data for rehydration experiments was collected on a PROTO AXRD benchtop instrument equipped with a DECTRIS MYTHEN2R 1D detector, using nickel-filtered $\mathrm{CuK}_{\alpha}(\lambda=0.154056 \AA)$ radiation. Rehydration was performed in a custom-made sealed sample holder ${ }^{15}$ kept at $98 \%$ relative humidity with the aid of a saturated aqueous solution of $\mathrm{K}_{2} \mathrm{SO}_{4}$.

\section{Variable temperature (VT)}

Variable temperature (VT) dehydration experiments and verification after impedance measurements were performed on a Bruker D8 Advance instrument equipped with a LYNXEYE XE-T detector using nickel-filtered $\mathrm{CuK}_{\alpha}(\lambda=0.154056 \AA)$ radiation. The setup was equipped with Anton Paar $\mathrm{CHC}_{\text {plus }}{ }^{+}$chamber. Diffractograms were collected in a stepwise fashion in a dry environment. After each collection ( $c a .15 \mathrm{~min}$ ), temperature in the chamber was raised by $1{ }^{\circ} \mathrm{C}$ at a rate of $1{ }^{\circ} \mathrm{C} \mathrm{min}{ }^{-1}$ and a new collection started.

\section{Crystal structures of ST2, ST1d and ST2d}

Crystal structures of ST2, ST1d and ST2d were determined by single crystal X-ray diffraction using a Bruker D8 APEX2 X-ray diffractometer and graphite-monochromated $\operatorname{MoK} \alpha(\lambda=$ $0.71073 \AA$ A) radiation. Structures were solved by intrinsic phasing in SHELXT ${ }^{16}$ and refined on $\mathrm{F}^{2}$ using SHELXL. ${ }^{17}$ Wherever possible, hydrogen atoms participating in hydrogen bonds were located from the electron density map. Crystallographic data in CIF format has been deposited with the Cambridge Structural Database (CSD), CCDC 1868681-1868685.

\section{Fourier-transform infrared attenuated total reflectance (FTIR-} ATR)

Fourier-transform infrared attenuated total reflectance (FTIRATR) studies were done on a Bruker VERTEX 70 instrument with a PLATINUM diamond crystal ATR unit. 
Thermogravimetric analysis and differential scanning calorimetry (TGA and DSC) analysis

Thermogravimetric analysis and differential scanning calorimetry (TGA and DSC) analysis was done on a Mettler-Toledo TGA DSC 1 Star system thermobalance using alumina crucibles under a stream of nitrogen $\left(50 \mathrm{~mL} \mathrm{~min}{ }^{-1}\right)$ and a heating rate of $5{ }^{\circ} \mathrm{C} \mathrm{min}{ }^{-1}$ from $25{ }^{\circ} \mathrm{C}$ until $200{ }^{\circ} \mathrm{C}$, and in a stream of air $(50$ $\mathrm{mL} \min ^{-1}$ ) at a heating rate of $10{ }^{\circ} \mathrm{C} \min ^{-1}$ from $200{ }^{\circ} \mathrm{C}$ to $700{ }^{\circ} \mathrm{C}$. Sample size was between $2 \mathrm{mg}$ and $10 \mathrm{mg}$.

\section{Deuterated ST1 and ZH}

Deuterated ST1 and $\mathbf{Z H}$ were prepared by first fully dehydrating the parent phases $\mathrm{NaMgFe}\left(\mathrm{C}_{2} \mathrm{O}_{4}\right)_{3} \cdot 9 \mathrm{H}_{2} \mathrm{O}$ (ST1) and $\mathrm{NaMgAl}\left(\mathrm{C}_{2} \mathrm{O}_{4}\right)_{3} \cdot 9 \mathrm{H}_{2} \mathrm{O}$ under vacuum at $70{ }^{\circ} \mathrm{C}$, after which the materials were dissolved in $\mathrm{D}_{2} \mathrm{O}$ and recrystallized in a dry $\mathrm{N}_{2}$ atmosphere. Deuteration was confirmed by FTIR-ATR, and the identity of samples was verified by PXRD.

\section{Alternative current (AC) impedance measurement}

Alternative current (AC) impedance measurement was performed by the conventional two-probe method. Samples (ST1, ST2, and ZH1) were pelletized about $\sim 1.2 \mathrm{~mm}$ in thickness and $2.5 \mathrm{~mm}$ in diameter. The pellet was connected to electrode with gold paste and gold wires (50 $\mu \mathrm{m}$ in diameter). The test is performed in a temperature- and humidity-controlled chamber, which was connected to a Solartron SI 1260 Impedance/GainPhase Analyzer and 1296 Dielectric Interface. The impedance measurement was executed in the frequency range from $1 \mathrm{~Hz}$ to $10 \mathrm{MHz}$ at $298 \mathrm{~K}$. Proton conductivity and activation energy barrier were estimated by eqn (1) and (2), where $\sigma$ is the conductivity $\left(\mathrm{S} \mathrm{cm}^{-1}\right), L$ is the measured sample thickness $(\mathrm{cm})$, $S$ is the electrode area $\left(\mathrm{cm}^{2}\right)$ and $Z$ is the impedance value. In eqn (2), $A$ is a pre-exponential factor, $k$ is the Boltzmann constant, and $E_{\mathrm{a}}$ is the activation energy of ionic conduction.

$$
\begin{gathered}
\sigma=\frac{L}{Z \times S} \\
\sigma T=A \exp \left(\frac{-E_{\mathrm{a}}}{k T}\right)
\end{gathered}
$$

\section{Water vapor sorption measurements}

Water vapor sorption measurements were carried out on $\mathbf{Z H}$, ST1, and ST2 using an automated micropore gas analyser BELSORP-max (MicrotracBEL Corp.). Before measurement, the water for adsorbate was degassed through a freeze-thaw cycle, and all samples were activated at $80^{\circ} \mathrm{C}$ under vacuum $\left(10^{-3} \mathrm{~Pa}\right)$ overnight. The water isotherms were measured at each equilibrium pressure by the static volumetric method at $298 \mathrm{~K}$ under $P / P_{0}=0.95$.

\section{Calorimetric measurements}

Calorimetric measurements to determine the enthalpies of dissolution $\left(\Delta H_{\mathrm{ds}}\right)$ of MOF samples (ST1, ST2 and ZH) and starting materials were performed using a CSC (Calorimetry Sciences Corporation) 4400 isothermal microcalorimeter at $25{ }^{\circ} \mathrm{C}$. Around $5 \mathrm{mg}$ of the sample was hand-pressed to form a pellet and dropped to a Teflon cell in the calorimeter, filled with $25 \mathrm{~g}$ of 5 molar aqueous $\mathrm{HCl}$ solution. The solvent was isothermally equilibrated for at least $3 \mathrm{~h}$ under mechanical stirring before the introduction of the sample, and the sample was allowed to dissolve in the cell for at least 2 hours, ensuring the return of baseline back to its initial position. In each experiment, the solvent in the cell was replaced with new, fresh solvent.

The calibration of the instrument was performed using a NIST standard reference material $\mathrm{KCl}$. The calibration was done by dissolving $15 \mathrm{mg}$ of the $\mathrm{KCl}$ pellet into $25 \mathrm{~g}$ of $\mathrm{H}_{2} \mathrm{O}$ (type1 , resistivity $=18.2 \mathrm{M} \Omega \mathrm{cm}$ ), which corresponds to a reference concentration of $0.008 \mathrm{~mol} \mathrm{~kg}^{-1}$ at $25{ }^{\circ} \mathrm{C}$. The calibration factor was obtained by correlating the integrated data with a known enthalpy of dissolution and dilution of $0.008 \mathrm{~mol} \mathrm{~kg}^{-1} \mathrm{KCl}$. For each sample, at least 4 measurements were performed. The uncertainties given in the result represents 95\% confidence interval. ${ }^{18}$ Due to incomplete dissolution of $\gamma$-FeOOH in 5 molar $\mathrm{HCl}$, its exact concentration was determined by inductively coupled plasma mass spectrometry (ICP-MS) using an Agilent 8900 ICP-MS. The supernatant after calorimetry measurement was diluted $10 \mathrm{X}$ and $100 \mathrm{X}$ with $3 \% \mathrm{HNO}_{3}$ (by volume) prepared from concentrated Trace Metal Grade $\mathrm{HNO}_{3}$ (Fisher Scientific) and deionized water (resistivity value of $18.2 \mathrm{M} \Omega \mathrm{cm}$ ).

\section{Results and discussion}

Synthetic ZH was prepared following our previous procedure (see ESI $\dagger$ ). ${ }^{11}$ Analysis of synthetic $\mathbf{Z H}$ by PXRD was consistent with the reported mineral structure, based on hcb-layers stacked along the $12.6 \AA$ crystallographic $c$-axis to form channels filled with $\mathrm{Mg}\left(\mathrm{H}_{2} \mathrm{O}\right)_{6}{ }^{2+}$ ions. The mineral ST exhibits a different structure, ${ }^{11}$ in which hcb-layers stack in $\mathrm{ABCA}^{\prime} \mathrm{B}^{\prime} \mathrm{C}^{\prime}$ fashion, resulting in a longer crystallographic $c$-axis of $\sim 37 \AA$ (Fig. $1 \mathrm{~b}$ and $\mathrm{c}$, where the $\mathrm{A}$ and $\mathrm{A}^{\prime}$ notations indicate layers with the same overall positions but rotated around the $c$-axis by $180^{\circ}$ relative to each other). ${ }^{9-11}$ However, a crystallographic study of synthetic samples by Piro et al. ${ }^{19}$ suggested that ST is isostructural to $\mathbf{Z H}$, i.e. exhibiting $\mathrm{AB}$ layer stacking along a $12.6 \AA$ $c$-axis. To resolve this discrepancy, we have now systematically investigated crystallization of ST under a variety of conditions,

Table 1 Crystallographic parameters of synthetic stepanovite polymorphs ST1 ${ }^{a}$ and ST2 collected at $298 \mathrm{~K}$ and $100 \mathrm{~K}$, and of corresponding dehydrated phases ST1d and ST2d

\begin{tabular}{llllll}
\hline Entry & Sample & $T(\mathrm{~K})$ & $a(\AA)$ & $c(\AA)$ & Space group \\
\hline 1 & ST1 $^{a}$ & $298^{a}$ & $9.8367(13)^{a}$ & $36.902(5)^{a}$ & $R 3 c^{a}$ \\
2 & ST1 & 100 & $9.8670(9)$ & $36.735(3)$ & $R 3 c$ \\
3 & ST2 & 298 & $17.0483(4)$ & $12.4218(4)$ & $P 3 c$ \\
4 & ST2 & 100 & $17.0033(11)$ & $12.4160(8)$ & $P 3 c$ \\
5 & ST1d & 298 & $9.7745(2)$ & $29.7940(11)$ & $R 3$ \\
6 & ST2d & 298 & $9.756(3)$ & $10.117(3)$ & $P 3$
\end{tabular}

${ }^{a}$ From ref. 11. 
unexpectedly revealing that slow evaporation from water produces large hexagonal plate-like crystals, whereas rapid evaporation produces elongated crystals with a hexagonal crosssection. Single crystal X-ray diffraction revealed that slowly grown plates (termed stepanovite 1, ST1) are isostructural to the mineral, with $\mathrm{ABCA}^{\prime} \mathrm{B}^{\prime} \mathrm{C}^{\prime}$ stacking of hcb-sheets and a $\sim 37 \AA$ axis perpendicular to large hexagonal crystal faces (Table 1, entries 1, 2). In contrast, elongated crystals (termed stepanovite 2, ST2) exhibit structural features and crystallographic parameters (Table 1, entries 3, 4) similar to $\mathbf{Z H}$, including AB-stacking of hcb-sheets and guest-filled channels parallel to a $12.4 \AA \mathrm{c}$-axis (Fig. 1e and f). Identical results were observed using X-ray diffraction data collected at room temperature and at $100 \mathrm{~K}$, confirming that the difference between structures of ST1 and ST2 is not related to temperature. The existence of ST2, a polymorph of synthetic stepanovite that is isostructural to zhemchuzhnikovite, offers an explanation of discrepancy between mineral structure and the synthetic sample structure reported by Piro et al. ${ }^{19}$

Stabilities of synthetic ST1, ST2, and ZH were investigated by room temperature acid dissolution calorimetry. ${ }^{\mathbf{1 8 , 2 0}}$ The enthalpies of formation of synthetic minerals were calculated from herein measured dissolution enthalpies $\left(\Delta H_{\mathrm{ds}}\right)$ of the minerals and relevant starting materials (oxalic acid, binary oxides, hydroxides, and oxyhydroxides), and a properly designed thermodynamic cycle (see ESI† for details and equations). This enabled the evaluation of relative energetic stabilities (Table 2) of both ST polymorphs and $\mathbf{Z H}$, as well as their enthalpies of formation from oxides $\left(\Delta H_{\mathrm{f}, \mathrm{ox}}\right)$ and from the elements $\left(\Delta H_{\mathrm{f}, \mathrm{el}}\right)$.

The very exothermic $\Delta H_{\mathrm{f}, \mathrm{ox}}$ indicates that the formation of ST1, ST2 and ZH from binary oxides is thermodynamically driven. The results also show that the difference in energetic stability of ST1 and ST2 is within the experimental error of calorimetric measurements. However, ZH has a noticeably more exothermic enthalpy of formation from oxides compared to ST polymorphs, indicating that structure stabilization by substitution of iron by aluminum is far larger than the effect of polymorphism. This trend of greater stability relative to binary oxide components for the aluminum compounds relative to the iron ones has been seen in many inorganic systems containing both $\mathrm{Al}^{3+}$ and $\mathrm{Fe}^{3+}$, such as in spinels, ${ }^{21}$ jarosite-alunite and natrojarosite-natroalunite solid solutions ${ }^{22}$ and zoisite, clinozoisite solid solutions. ${ }^{23}$

Although ST1 and ST2 are very similar in enthalpy, there is some indication from different growth conditions that ST2 is

Table 2 Measured enthalpies of solution in $5 \mathrm{~N} \mathrm{HCl}\left(\Delta H_{\mathrm{s}}, \mathrm{kJ} \mathrm{mol}^{-1}\right)$ and calculated enthalpies of formation from oxides $\Delta H_{\mathrm{f}, \mathrm{ox}}$ and elements $\Delta H_{\mathrm{f} \text {,el }}$ of synthetic ST1, ST2 and ZH (for the rest of the thermodynamic data see ESI)

\begin{tabular}{llll}
\hline Sample & $\Delta H_{\mathrm{s}}$ & $\Delta H_{\mathrm{f}, \mathrm{ox}}$ & $\Delta H_{\mathrm{f}, \mathrm{el}}$ \\
\hline ST1 & $91.38 \pm 0.66$ & $-422.31 \pm 2.29$ & $-5847.41 \pm 2.59$ \\
ST2 & $92.15 \pm 0.47$ & $-423.07 \pm 2.24$ & $-5848.19 \pm 2.55$ \\
ZH & $64.81 \pm 1.06$ & $-434.03 \pm 3.20$ & $-6113.98 \pm 3.43$
\end{tabular}

a kinetic polymorph, while $\mathbf{S T 1}$ is thermodynamically preferred. This is supported by the observation that ST2 converts to ST1 by shaking or brief milling with small amounts of water. The metastable character of ST2 compared to ST1 would agree with Goldsmith's simplexity principle, ${ }^{24}$ stating that kineticallyfavored phases are often structurally simpler than their thermodynamically stable counterparts. ${ }^{25}$ Our calculations of information-based structural complexity parameters ${ }^{26}$ show that ST1 has a very complex structure $\left(I_{\mathrm{G}}=5.618\right.$ bits/atom; $\left.I_{\mathrm{G}, \text { total }}=1617.979 \mathrm{bits} / \mathrm{cell}\right)$, whereas the structure of ST2 is intermediate in complexity $\left(I_{\mathrm{G}}=4.099\right.$ bits/atom; $I_{\mathrm{G} \text {,total }}=$ $393.510 \mathrm{bits} / \mathrm{cell})$.

Analysis by TGA (see ESI $\dagger$ ) and variable-temperature powder X-ray diffraction (VT-PXRD, Fig. 2a and b) show that ST1 and ST2 lose three equivalents of guest water molecules upon mild heating, forming new crystalline phases ST1d and ST2d, respectively. Furthermore, crystals of ST1 and ST2 retained their integrity upon dehydration, providing diffraction-quality crystals of ST1d and ST2d. Structure analysis shows that dehydration leads to partial (ST1) or complete (ST2) corrugation of hcblayers (Fig. 3), which lowers the space group symmetry of ST1d and ST2d compared to the parent phases (Table 1, entries 5, 6).

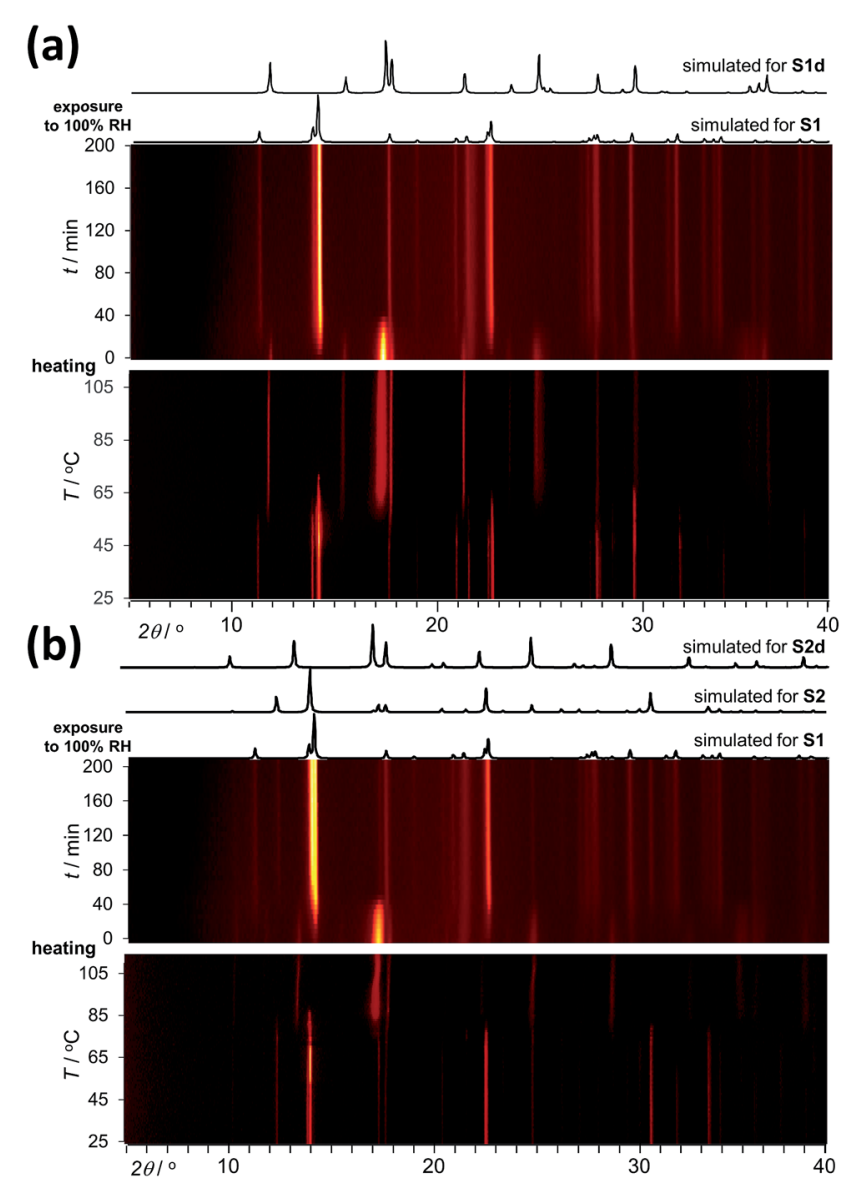

Fig. 2 PXRD data for a powdered sample of (a) ST1 and (b) ST2 being (bottom) first dehydrated by heating $\left(2^{\circ} \mathrm{C}\right.$ per hour, from $25^{\circ} \mathrm{C}$ to 110 ${ }^{\circ} \mathrm{C}$ ) and subsequently (top) exposed to $100 \% \mathrm{RH}$ at room temperature. Simulated PXRD patterns for ST1, ST2, ST1d and ST2d are shown above the in situ data plots 
(a)

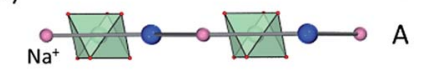

(b)
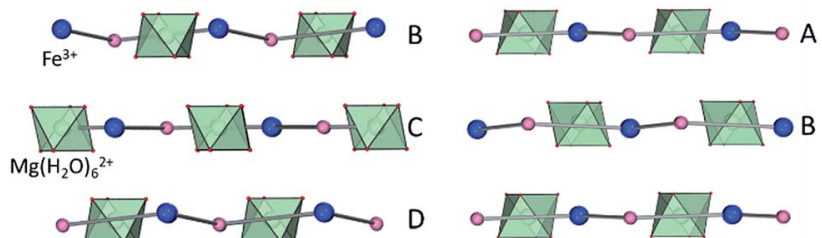

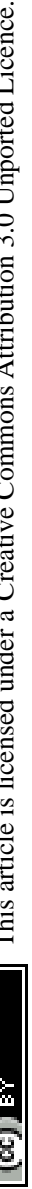

In ST1d the hcb-layers adopt a more complex ABCDEF repeat pattern as a result of the original $\mathrm{ABCA}^{\prime} \mathrm{B}^{\prime} \mathrm{C}^{\prime}$-stacking now being combined with alternation of flat and corrugated sheets. In ST2d, each hcb-sheet is corrugated, preserving the AB-stacking of ST2.

The accessibility of bulk synthetic samples for ST1, ST2 and ZH enabled the evaluation of suspected proton conductivity by AC impedance measurement on compacted powder pellets. For proton conductivity, all Nyquist plots were obtained under controlled relative humidity $(\mathrm{RH})$ and temperature (see ESI $\dagger$ ). Impedance measurements revealed significant enhancement of proton conductivity $(\sigma)$ in ST1, ST2 and ZH with relative humidity (Fig. 4a). At 90\% RH synthetic ZH exhibits a high $\sigma$ of almost $3 \times 10^{-3} \mathrm{~S} \mathrm{~cm}^{-1}$, on par with some of the highest room temperature proton conductive MOFs. ${ }^{27-29}$ Proton conductivity of synthetic ST1 is also high, but almost an order of magnitude lower than that of $\mathbf{Z H}$. Both ST1 and ZH remained crystalline upon conductivity evaluation, as verified by PXRD patterns recorded after the measurements. Proton conductivity for ST2 could not be measured above $70 \% \mathrm{RH}$, due to deliquescence at higher RH values. However, at all explored RH levels below 70\% the conductivity of ST2 was similar to that of ZH and consistently higher than for ST1. Indeed, at $70 \% \mathrm{RH}$ and $25{ }^{\circ} \mathrm{C}$ the proton conductivity of ST2 is among the top values reported for MOFs at modest humidity and room temperature..$^{30}$

The two main mechanisms for proton diffusion are classfied by activation energy $\left(E_{\mathrm{a}}\right)$ : the vehicle mechanism $\left(E_{\mathrm{a}}>0.4 \mathrm{eV}\right)$ and the Grotthuss mechanism $\left(E_{\mathrm{a}}<0.4 \mathrm{eV}\right) .{ }^{31,32}$ The activation energies for proton conduction in ST1 $(0.59 \mathrm{eV})$ and ZH $(0.37 \mathrm{eV})$ at $90 \% \mathrm{RH}$ were established using the Arrhenius method (Fig. 4b). The values are consistent with a mixed GrotthussVehicle proton diffusion mechanism, which puts these materials in the group of superionic conductors, as described by Colomban et al..$^{33}$ The $E_{\mathrm{a}}$ for $\mathbf{S T 2}$ is considerably larger $(1.31 \mathrm{eV})$ compared to ZH and ST1, due to measurements being performed at $70 \%$ RH. In addition, PXRD pattern of ST2 after conductivity studies at different temperatures revealed partial structural transformation to ST1, which could also have affected the high $E_{\text {a }}$ (see ESI†).
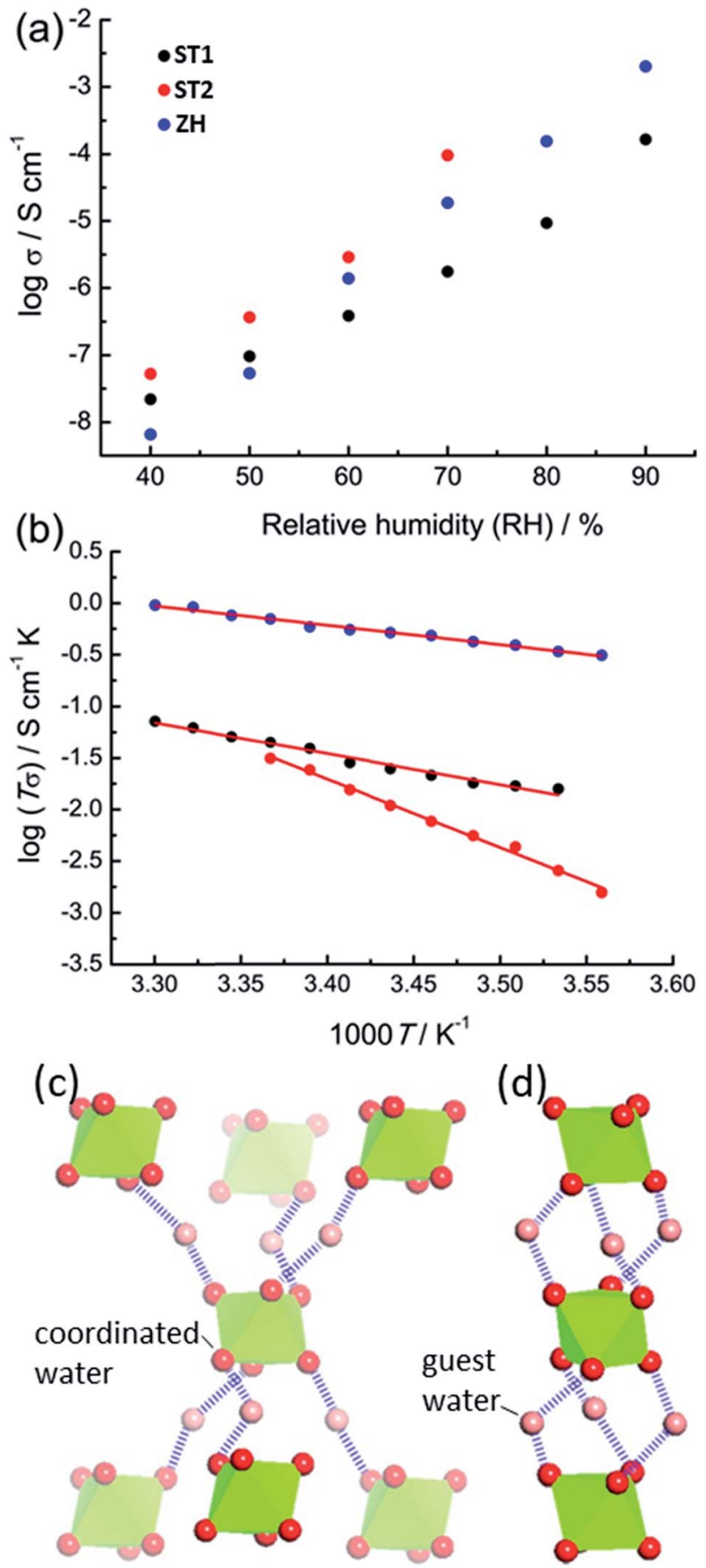

Fig. 4 (a) Proton conductivity $(\sigma)$ at $25^{\circ} \mathrm{C}$ for synthetic ST1 (black), ST2 (red) and $\mathrm{ZH}$ (blue) at different $\mathrm{RH}$. (b) Arrhenius plots of the proton conductivities for ST1(black, at 90\% RH), ST2 (red, at 70\% RH), and ZH (blue, at $90 \% \mathrm{RH}$ ), with least-squares fits shown as solid lines. Fragments of hydrogen-bonded networks involving guest water molecules and $\mathrm{Mg}\left(\mathrm{H}_{2} \mathrm{O}\right)_{6}{ }^{2+}$ ions in: (c) ST1 and (d) ST2. For clarity, hcb-layers are omitted and $\mathrm{Mg}\left(\mathrm{H}_{2} \mathrm{O}\right)_{6}{ }^{2+}$ ions are shown as green octahedra.

It was reported that high proton conductivity in oxalate MOFs $\left(\geq 10^{-3} \mathrm{~S} \mathrm{~cm}^{-1}\right.$ at $\left.25{ }^{\circ} \mathrm{C}, 98 \% \mathrm{RH}\right)$ requires the inclusion of additional proton-carrying guests, such as weakly acidic $\mathrm{NH}_{4}{ }^{+}$or adipic acid. ${ }^{14,34,35}$ In such systems, conductivity is strongly 
influenced by the type and organization of proton-carrying guests. $^{36}$ As the conductivities and activation energies in ST1, ST2 and ZH are comparable to such systems, it is likely that $\mathrm{Mg}\left(\mathrm{H}_{2} \mathrm{O}\right)_{6}{ }^{2+}$ ions, in which the proton-donating ability of water molecules is enhanced by coordination to $\mathrm{Mg}^{2+}$, act as such protic guests. Differences in $\sigma$ between ST1, ST2 and ZH can tentatively be related to different topologies of hydrogen-bonded frameworks formed by $\mathrm{Mg}\left(\mathrm{H}_{2} \mathrm{O}\right)_{6}{ }^{2+}$ ions and water guests (Fig. 4c). As ST1 and ST2 have an identical composition, and ST1 and $\mathbf{Z H}$ share the same crystallographic structure, it is reasonable to assume that the difference in conduction properties of ST1 and ST2 are associated with ST2 adopting a ZH-like hydrogen-bonded guest structure. To verify whether conductivity is due to proton conduction or contributions of other ionic species, additional impedance measurements were performed on deuterated ST1 and $\mathbf{Z H}$ at $25{ }^{\circ} \mathrm{C}$ and $\mathrm{ca}$. $70 \%$ saturated $\mathrm{D}_{2} \mathrm{O}$ vapor (see ESI $\dagger$ ). ${ }^{37}$ Measurements on both samples revealed a reduction in conductivity upon deuteration, which is consistent with proton conduction. Specifically, measurements on deuterated ST1 revealed a $\mathrm{ca}$. 1.3-fold reduction in conductivity (from $1.76 \times$ $10^{-6} \mathrm{~S} \mathrm{~cm}^{-1}$ to $1.40 \times 10^{-6} \mathrm{~S} \mathrm{~cm}^{-1}$ ) along with a comparable activation energy $(0.51 \mathrm{eV})$. For deuterated $\mathbf{Z H}$ a more significant 5.8 -fold reduction in conductivity was observed (from $1.87 \times$ $10^{-5} \mathrm{~S} \mathrm{~cm}^{-1}$ to $\left.3.22 \times 10^{-6} \mathrm{~S} \mathrm{~cm}^{-1}\right)$, along with a small increase in activation energy $(0.51 \mathrm{eV}$, see ESI $\dagger)$.

\section{Conclusions}

In summary, we have shown that MOF minerals zhemchuzhnikovite and stepanovite can exhibit high proton conductivity, enabled by hydrogen-bonding networks involving interstitial water molecules, hydrated metal cation guests and the oxalate based-framework. At the same time, we report the possibility of polymorphism in stepanovite, which enabled observing the effect of hydrogen-bonded framework topology on proton conductivity of an oxalate-based MOF. All of the MOF minerals studied were found to be very stable with respect to the binary oxides, and substitution of iron by aluminum was found to improve the stability of zhemchuzhnikovite. Upon heating, stepanovite polymorphs lose included water guests in a crystalto-crystal fashion, i.e. without disrupting the 2-dimensional open framework layers.

Overall, these results are highly significant in the contexts of geology and materials chemistry, as they demonstrate that naturally occurring MOFs containing small oxalate ligands are thermodynamically stable phases that exhibit functional properties comparable to previously reported advanced materials, including high proton conductivity and framework retention at elevated temperature. We note that this work also presents a simple design for synthesizing high-performing proton conductive materials without sacrificing thermodynamic stability or requiring complex organic components. We are currently investigating the properties of other MOFs based on this design.

\section{Conflicts of interest}

There are no conflicts to declare.

\section{Acknowledgements}

This work was funded by NSERC Discovery Grant (RGPIN-201706467) and NSERC E. W. R. Steacie Memorial Fellowship (SMFSU 507347-17). Calorimetry at UC Davis was supported by the U.S. Department of Energy Office of Science, grant DESC0016573. D.-W. Lim, and H. Kitagawa acknowledge the support from the ACCEL program, Japan Science and Technology Agency (JST), JPMJAC1501.

\section{Notes and references}

1 T. Echigo and M. Kimata, Can. Mineral., 2010, 48, 1329-1357.

2 I. Huskić and T. Friščić, Acta Crystallogr., Sect. B: Struct. Sci., Cryst. Eng. Mater., 2018, 74, 539-559.

3 S. A. Benner, K. G. Devine, L. N. Matveeva and D. H. Powell, Proc. Natl. Acad. Sci. U. S. A., 2000, 97, 2425-2430.

4 H. E. Maynard-Casely, M. L. Cable, M. J. Malaska, T. H. Vu, M. Choukroun and R. Hodyss, Am. Mineral., 2018, 103, 343-349.

5 (a) T. Echigo and M. Kimata, Phys. Chem. Miner., 2008, 35, 467-475; (b) T. Yamada, M. Sadakkiyo and H. Kitagawa, J. Am. Chem. Soc., 2009, 131, 3144-3145.

6 (a) D. R. Hummer, B. C. Noll, R. M. Hazen and R. T. Downs, Am. Mineral., 2017, 102, 1129-1132; (b) C. B. Storm, J. Krane, T. Skjetne, N. Telnaes, J. F. Branthaver and E. W. Baker, Science, 1984, 223, 1075-1076.

7 https://mineralchallenge.net/.

8 R. M. Hazen, D. R. Hummer, G. Hystad, R. T. Downs and J. J. Golden, Am. Mineral., 2016, 101, 889-906.

9 Y. N. Knipovich, A. I. Komkov and E. I. Nefedov, Tr. Vses. Neft. Nauchno-Issled. Geologorazved. Inst., 1963, 96, 131-135.

10 M. Fleischer, Am. Mineral., 1964, 49, 439-448.

11 I. Huskić, I. V. Pekov, S. V. Krivovichev and T. Friščić, Sci. $A d v .$, 2016, 2, e1600621.

12 (a) M. Sadakiyo, T. Yamada and H. Kitagawa, ChemPlusChem, 2016, 81, 691-701; (b) M. Dan and C. N. R. Rao, Angew. Chem., Int. Ed., 2006, 45, 281-285; (c) C. N. R. Rao, S. Natarajan and R. Vaidhyanathan, Angew. Chem., Int. Ed., 2004, 43, 1466-1496; (d) R. Vaidhyanathan, S. Natarajan, A. K. Cheetham and C. N. R. Rao, Chem. Mater., 1999, 11, 3636-3642.

13 (a) H. Ōkawa, A. Shigematsu, M. Sadakiyo, T. Miyagawa, K. Yoneda, M. Ohba and H. Kitagawa, J. Am. Chem. Soc., 2009, 131, 13516-13522; (b) T. Yamada, M. Sadakiyo, A. Shigematsu and H. Kitagawa, Bull. Chem. Soc. Jpn., 2016, 89, 1-10; (c) S. Descurtins, H. W. Schmalle, P. Schneuwly, J. Ensling and P. A. Gütlich, J. Am. Chem. Soc., 1994, 116, 9521-9528.

14 (a) D.-W. Lim, M. Sadakiyo and H. Kitagawa, Chem. Sci., 2019, 10, 16-33; (b) M. Sadakiyo, T. Yamada, K. Honda, H. Matsui and H. Kitagawa, J. Am. Chem. Soc., 2014, 136, 7701-7707.

15 I. Huskić, J.-C. Christopherson, K. Užarević and T. Friščić, Chem. Commun., 2016, 52, 5120-5123.

16 G. M. Sheldrick, Acta Crystallogr., Sect. A: Found. Adv., 2015, 71, 3-8. 
17 G. M. Sheldrick, Acta Crystallogr., Sect. A: Found. Adv., 2015, 71, 3-8.

18 J. T. Hughes, T. D. Bennett, A. K. Cheetham and A. Navrotsky, J. Am. Chem. Soc., 2013, 135, 598-601.

19 O. E. Piro, G. A. Echeverría, A. C. González-Baró and E. J. Baran, Phys. Chem. Miner., 2016, 43, 287-300.

20 Z. Akimbekov, A. D. Katsenis, G. P. Nagabushana, G. Ayoub, M. Arhangelskis, A. J. Morris, T. Friščić and A. Navrotsky, J. Am. Chem. Soc., 2017, 139, 7952-7957.

21 A. Navrotsky and O. J. Kleppa, J. Inorg. Nucl. Chem., 1968, 30, 479-498.

22 C. Drouet, K. L. Pass, D. Baron, S. Draucker and A. Navrotsky, Geochim. Cosmochim. Acta, 2004, 68, 2197-2205.

23 E. A. Smelik, G. Franz and A. Navrotsky, Am. Mineral., 2001, 86, 80-91.

24 J. R. Goldsmith, J. Geol., 1953, 61, 439-451.

25 (a) S. V. Krivovichev, Mineral. Mag., 2013, 77, 275-326; (b) J. Cempirek, E. S. Grew, A. R. Kampf, C. Ma, M. Novak, P. Gadas, R. Skoda, M. Vasinova-Galiova, F. Pezzotta, L. A. Groat and S. V. Krivovichev, Am. Mineral., 2016, 101, 2108-2117; (c) J. Plášil, V. Petříček and J. Majzlan, Acta Crystallogr., Sect. A: Found. Adv., 2017, B73, 856-862; (d) J. Majzlan, E. Dachs, A. Benisek, J. Plášil and J. Sejkora, Eur. J. Mineral., 2018, 30, 259-275.

26 S. V. Krivovichev, Angew. Chem., Int. Ed., 2014, 53, 654-661. 27 X. Meng, H.-N. Wang, S.-Y. Song and H.-J. Zhang, Chem. Soc. Rev., 2017, 46, 464-480.

28 M. R. Karim, K. Hatakeyama, M. Koinuma and S. Hayami, J. Mater. Chem. A, 2017, 5, 7243-7256.
29 P. Ramaswamy, N. E. Wong and G. K. H. Shimizu, Chem. Soc. Rev., 2014, 43, 5913-5932.

30 B. Joarder, J.-B. Lin, Z. H. Romero and G. K. H. Shimizu, J. Am. Chem. Soc., 2017, 139, 7176-7179.

31 K.-D. Kreuer, A. Rabenau and W. Weppner, Angew. Chem., Int. Ed., 1982, 21, 208-209.

32 (a) C. J. T. de Grotthuss, Ann. Chim., 1806, 58, 54-73; (b) N. Agmon, Chem. Phys. Lett., 1995, 244, 456-462.

33 P. Colomban and A. Novak, J. Mol. Struct., 1988, 177, 277308.

34 M. Sadakiyo, T. Yamada and H. Kitagawa, J. Am. Chem. Soc., 2009, 131, 9906-9907.

35 E. Pardo, C. Train, G. Gontard, K. Boubekeur, O. Fabelo, H. Liu, B. Dkhil, F. Lloret, K. Nakagawa, H. Tokoro, S. Ohkoshi and M. Verdaguer, J. Am. Chem. Soc., 2011, 133, 15328-15331.

36 (a) M. Sadakiyo, T. Yamada and H. Kitagawa, J. Am. Chem. Soc., 2014, 136, 13166-13169; (b) S. Miyatsu, M. Kofu, A. Nagoe, T. Yamada, M. Sadakiyo, T. Yamada, H. Kitagawa, M. Tyagi, V. García Sakai and O. Yamamuro, Phys. Chem. Chem. Phys., 2014, 16, 17295-17304.

37 (a) S. C. Sahoo, T. Kundu and R. Banerjee, J. Am. Chem. Soc., 2011, 133, 17950-17958; (b) B. W. Kang, J. H. Song, K. J. Lee, H. G. Lee, J. E. Kim, H. Y. Lee, J. Y. Kim and C. S. Hong, J. Mater. Chem. A, 2017, 5, 17492-17498; (c) Q. Tang, Y. Liu, S. Liu, D. He, J. Miao, X. Wang, G. Yang, Z. Shi and Z. Zheng, J. Am. Chem. Soc., 2014, 136, 12444-12449. 